\title{
A Multi-Dimensional Clustering Applied to Classify the Typology of Urban Public Parks in Bangkok Metropolitan Area, Thailand
}

\author{
Chompoonut Kongphunphin ${ }^{1}$ and Manat Srivanit ${ }^{1,2, *(D)}$ \\ 1 Faculty of Architecture and Planning, Thammasat University, Pathumthani 12121, Thailand; \\ chompooploy2012@gmail.com \\ 2 Center of Excellent in Urban Mobility Research and Innovation (CoE-UMRI), Thammasat University, \\ Pathumthani 12121, Thailand \\ * Correspondence: s.manat@gmail.com; Tel.: +66-2-986-9605
}

Citation: Kongphunphin, C.; Srivanit, M. A Multi-Dimensional Clustering Applied to Classify the Typology of Urban Public Parks in Bangkok Metropolitan Area, Thailand. Sustainability 2021, 13, 11426. https://doi.org/10.3390/ su132011426

Academic Editor: Thomas A. Clark

Received: 1 August 2021

Accepted: 12 October 2021

Published: 15 October 2021

Publisher's Note: MDPI stays neutral with regard to jurisdictional claims in published maps and institutional affiliations.

Copyright: (c) 2021 by the authors. Licensee MDPI, Basel, Switzerland. This article is an open access article distributed under the terms and conditions of the Creative Commons Attribution (CC BY) license (https:/ / creativecommons.org/licenses/by/ $4.0 /)$.

\begin{abstract}
Public parks are public spaces that support community activities and enhance the environmental quality of a city. Depending on the local urban context in terms of socio-economic conditions and location, the physical characteristics and particular uses of each public park may vary from each other. Accordingly, urban public parks and their uses reflect the characteristics of communities and neighborhoods where the public parks are located. The aim of this study is to apply analytical approaches using a multi-dimensional clustering method to classify multivariate characteristics of public parks into typologies that combine a set of criteria related to internal park attributes and external physical environments around parks in an urban context of Bangkok Metropolitan Area, Thailand. An analysis of a multi-dimensional data set from 30 public parks resulted in six identified clusters of characteristics of urban park areas. The study demonstrates how the context-specific typology can assist local urban planners, policymakers, and government authorities when considering management strategies for public parks in Bangkok areas.
\end{abstract}

Keywords: urban public parks; multi-dimensional clustering method; park typology; park characteristics

\section{Introduction}

Public parks are a part of the public spaces of a city. Cities are rediscovering the potential of urban parks to advance environmental sustainability and enhance its social amenities [1-6]. Urban public parks provide important benefits especially in highly congested cities. Public parks provide opportunities for community residents to relax in a natural environment, socialize, engage in physical activity and other leisure pursuits, that bring together people and help develop a sense of community [7-10]. Moreover, public parks are vital in supporting biodiversity and promoting important ecosystems in urban areas that improve a city's physical environment overall [11-15]. At the same time, public parks help to create a sense of place by supporting community activities that improve the quality of life for all who live in the city and especially for communities where the public parks are located $[10,16,17]$. A fundamental concern therefore for both urban policymakers and urban designers is whether the provision of parks is being efficiently used and meets the needs of the community where it is located.

Urban park studies often ignore the distinctive physical and geographic dimensions and context of these spaces, including their available facilities and amenities, spatial distribution, landscaping, built and socio-economic context, and other physical, social, and environmental characteristics of place $[9,10,18]$. In fact, the physical features of parks identify the unique character of the district where the public parks are located. They can also define the landscape and townscape structure and identity of settlements [19-21]. Moreover, each urban public space has become an indispensable part of residents' lives, playing a positive role in facilitating urban greening, improving public outdoor recreation and education, rebuilding city image, and ensuring sustainable urban development. Public 
spaces are distinguished by their size, nature elements, recreational activities, and available facilities which are also reflected in the valued characteristics of public parks [22-24]. Visual and symbolic features within public parks include unique images of places that communicate unforgettable memories in users $[25,26]$. The surrounding context of public parks' locations such as building density, land use, and services and facilities correlates with its surrounding environment features [23,27] of urban density, compactness, and mixed use $[1,8,10,25,28]$.

Public parks are classified into many types based on various principles $[10,21,24]$. There are spatial variables that have been defined and measured, and each city or country has its criteria to classify them. There are generally two methods used in open space categorization, namely typology and classification [29]. While the typology focuses on the type of spaces and includes visual and aesthetic characteristics, shapes, forms, and patterns such as squares, plazas, streets, and parks [30,31], the classification focuses on the use and value of public spaces that represent the character and relationship between public spaces and their surrounding contexts, involving roles, purposes, and the ways they are actually used $[25,26,32]$. Additionally, the classification method in classifying public parks generally covers three approaches, namely the catchment hierarchy, function, and landscape environmental characteristics [29]. The catchment hierarchy refers to users of public parks that are influenced by the geographical area being serviced, size, level of public park uses, and significance $[33,34]$. The function refers to the roles of the public parks that are influenced by actual usage and activities such as recreation, sport, and nature $[35,36]$. Lastly, the landscape environment characteristics refer to shapes, forms, and contexts of public parks that are influenced by the size, presence of facilities, and availability activities [37-39].

From the above, it can be concluded that the quality of public park systems is influenced by a range of factors including both internal park attributes and external factors that influence a user's behavior in selecting an urban park. In the case of the external factors, it is the surrounding context of the public park's location and urban configuration that have been associated with the influence of proximity and attractiveness of urban public parks. Moreover, many scholars [10,23] have focused on the physical surroundings of public parks' locations such as landscape environment, building density, building use, land use, and natural elements, whereas the internal factors refer to the characteristics and elements of public parks such as the important scenic, historic, and natural elements of the parks. Most researchers have focused on the user, level of use, size of users, role of users, design elements, recreation facilities, and visual quality of park scenes, rather than the context of social and spatial disparity of urban park services [35,37,38].

The specific objectives of this research are three-fold. First, this study attempts to classify the types of public parks located in an urban area of Bangkok, Thailand by using a multi-dimensional procedure for empirically classifying city parks according to their potential influencing external and internal factors on the spatial context that define the attractiveness of public parks to advance urban park research methods. Second, a cluster analysis is applied to determine the appropriate number of park clusters based on their similarities with respect to external and internal factors. Finally, the distribution of various park typologies was mapped, facilitating a spatial and visual examination of the study results, including how different park types are distributed across the city relative to zones of various population density in Bangkok. The results from this study can provide insights, suggestions, guidelines, or operative recommendations into Bangkok's urban parks planning, policy, and design and management.

\section{Study Area}

Bangkok or Bangkok Metropolitan Area (BMA) is the capital city of Thailand and is located by the geographic coordinate system at the latitude of $13^{\circ} 45^{\prime} 14.33^{\prime \prime} \mathrm{N}$ and longitude of $100^{\circ} 30^{\prime} 5.18^{\prime \prime} \mathrm{E}[40,41]$. BMA consists of 50 districts covering an area of approximately 1569 square kilometers in total [42]. It is also an autonomous area of Thailand that is 
about $80 \%$ urbanized [41,42]. The average population density is 3619 persons per square kilometer. However, in the heart of the city its population density rises to 19,500 persons per square kilometer. The metropolitan area is also divided into three different zones, by the population density and land-use intensity, as the inner zone, the middle zone, and the outer zone (see Figure 1) [43]. Specifically, the inner zone has the highest concentrations of population and urbanization where the old residential community, the governmental offices, the business and services center, the educational institutions, and the historic conservation areas are located, whereas the middle zone has the secondary commercial area, supporting the growth from the inner-city developments. Therefore, the inner-city area and its buildings are mostly used for business and commercial activities. In contrast, the outer zone is occupied by agricultural activities, residential uses, green zones, and the drainage basin for the downtown area $[41,44]$.

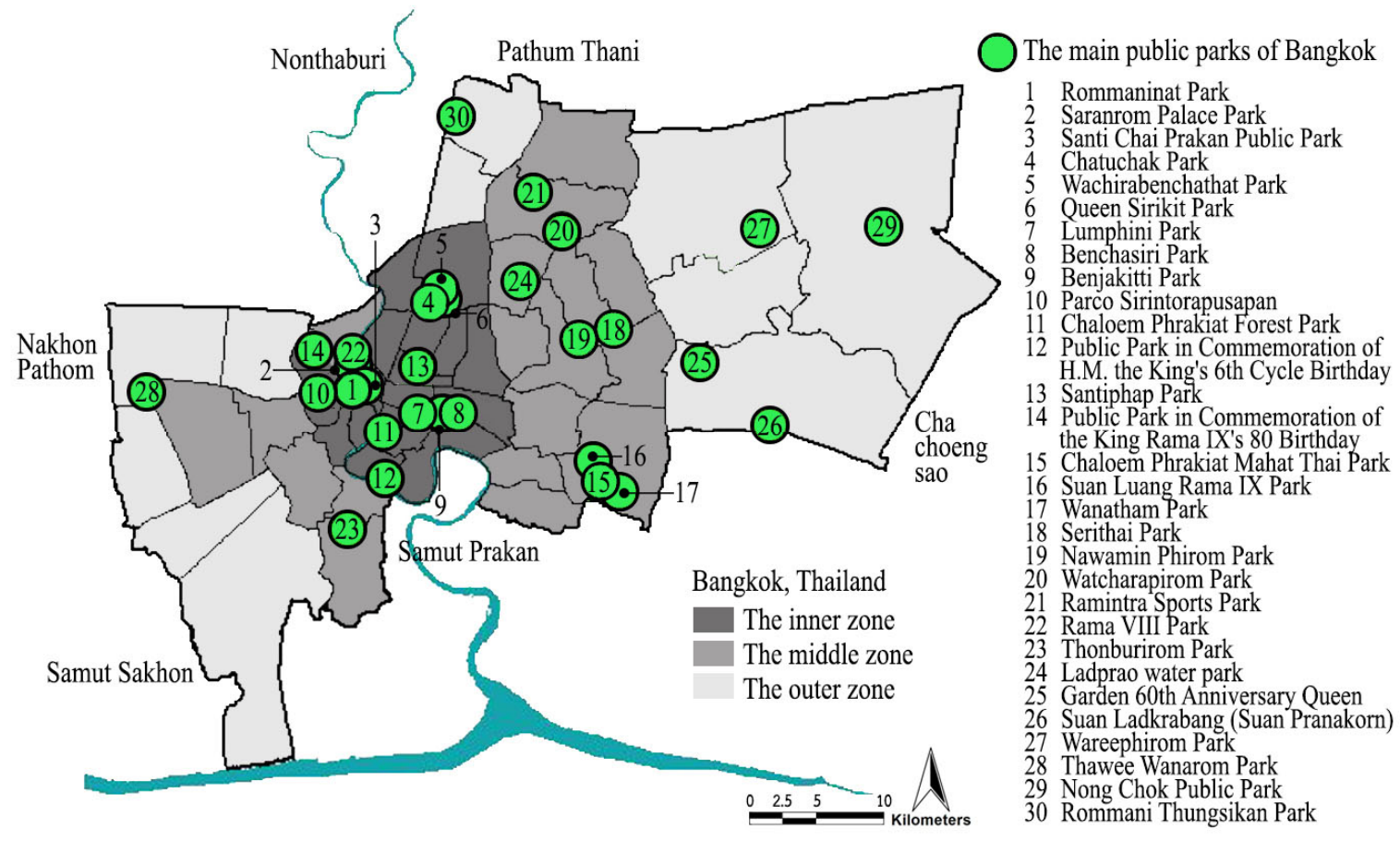

Figure 1. Spatial distribution of 30 main public parks in the study area.

Regarding the greenhouse effect, the Bangkok Authority aims to reduce greenhouse gas by 20-25 percent by the year 2030 as per the Paris Agreement. Accordingly, the Green Bangkok 2030 Project was launched in October 2019 to support urban sustainability and increase the quality of the green spaces [45]. The objectives of the project are to (1) increase the green spaces to 10 square meters per person, (2) grow the public green spaces by at least 50 percent in all districts in Bangkok so that they can be reached within $400 \mathrm{~m}$ or $5 \mathrm{~min}$ by walking from residential areas, and (3) expand the urban tree canopy to 30 percent of Bangkok. For further illustration, the present ratio of the Bangkok Green Zone is presented in the following Table 1 [42,45], where it is shown that Bangkok has 7831 parks in total, covering 37.2 square kilometers or 9192 acres. Therefore, the ratio of its green spaces to its population is about 6.7 square meters per person, which is still below the minimum standard that the World Health Organization (WHO) has standardized as 9 square meters per person.

This research is based on data collected from the first phase for implementing a total of 30 main park improvements in accordance with the 20-year Bangkok Development Plan (2013-2032) according to the Green Bangkok 2030 project [45]. More details of the locations of each park that are spread over the inner, middle, and outer zones of Bangkok are shown in Figure 1. 
Table 1. Main types of public parks in Bangkok.

\begin{tabular}{cccc}
\hline \multirow{2}{*}{ Types of Parks } & Number of Parks & \multicolumn{2}{c}{ Total Area of Parks } \\
\cline { 3 - 4 } & & Sq km & Proportion (\%) \\
\hline Pocket park & 3758 & 3.97 & 47.99 \\
\hline Neighborhood park & 1060 & 9.77 & 13.54 \\
\hline Community park & 80 & 6.12 & 1.02 \\
\hline District park & 19 & 7.49 & 0.24 \\
\hline City park & 2 & 2.32 & 0.03 \\
\hline Street garden park & 2892 & 7.23 & 36.93 \\
\hline Specialized garden park & 14 & 0.29 & 0.18 \\
\hline Not specified & 6 & 0.003 & 0.08 \\
\hline Total & 7831 & 37.20 & 100.00 \\
\hline
\end{tabular}

\section{Methodology and Study Framework}

The primary objective of this research is to classify the major urban public parks using multi-dimensional clustering that group public parks according to the factors that influence their use. The methodology proceeds in three main stages, as shown in Figure 2. The first stage involved setting the variables that may influence the use of public parks in the city by applying a geographical measure to quantify the influences of the internal and external factors on urban park use. In the second stage, factor analysis is applied to identify potential influencing factors on urban park use, which were used as the input features in the cluster analysis to generate the typology of urban public parks. Finally, cluster analysis is used as the statistical method for generating the groups of urban parks with combinations of the two dimensions of internal and external factors that affected urban park utilization in BMA.

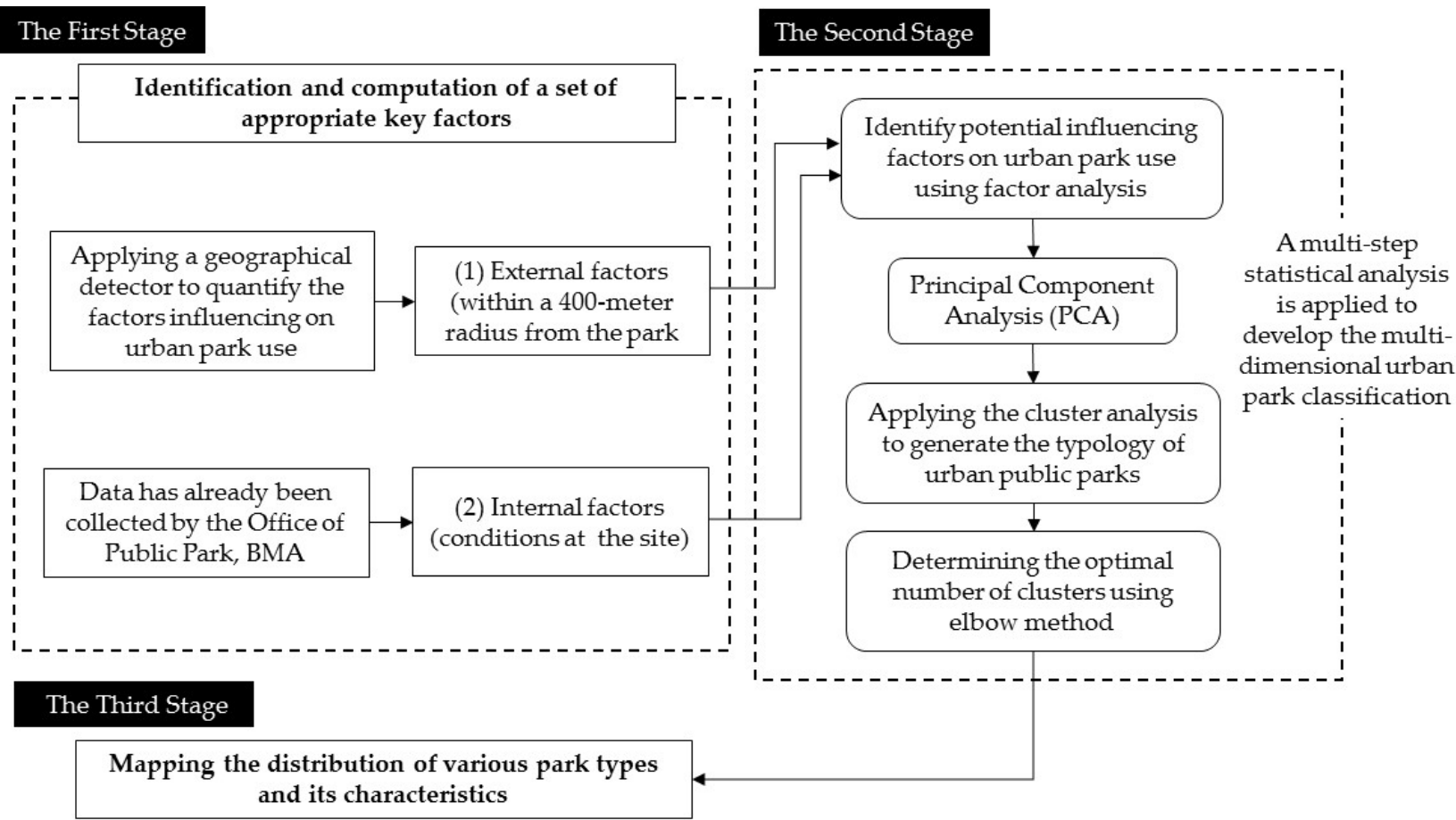

Figure 2. A framework for multi-dimensional clustering for classifying the typology of urban public parks. 


\subsection{Potential Influencing Factors on Urban Park Use}

The first process involves the specification of the suitable variables and calculating their values that are relevant to the spatial physical environment as per the literature review. Existing evidence suggested that myriad factors would affect the park use, which include the internal factors, external factors and the park's reputation. Internal factors indicate attributes related to the initial design of parks such as park size, water, recreational facilities [46-48]. External factors refer to influencing factors located around the park, without consideration of park properties such as population density around the park, traffic convenience to the park, variety of recreational facilities [49,50]. Additionally, the number of users of the major public parks in Bangkok and their facilities was determined from the secondary data obtained from the Office of Public Parks, Department of Strategy and Evaluation [45]. A geographic information system (GIS) was used to analyze important aspects of the spatial data. Referring to previous studies, 19 subfactors from both external and internal factors (as demonstrated in Table 2) were taken into consideration. Next, we provide a detailed description regarding how the 19 subfactors were calculated based on the multi-sourced data.

Table 2. Descriptions of the potential factors influencing the park service area.

\begin{tabular}{|c|c|c|}
\hline Category & $\begin{array}{c}\text { Factor } \\
\text { (Abbreviation) }\end{array}$ & Description (Units) \\
\hline \multirow{9}{*}{$\begin{array}{l}\text { External } \\
\text { factor } \\
\text { (within } \\
\text { a } 400-\mathrm{m} \\
\text { radius from } \\
\text { the park) }\end{array}$} & Degree of land-use mix & $\begin{array}{l}\text { The combination of the number of functional mix in neighborhood development } \\
\text { such as residential, commercial activity, mixed-use buildings, manufacturing and } \\
\text { processing activities, and educational and governmental services }\end{array}$ \\
\hline & Community component & $\begin{array}{l}\begin{array}{l}\text { Number of pivotal areas of the Thai community (educational areas and } \\
\text { religious institutions) }\end{array} \\
\end{array}$ \\
\hline & Religious diversity & Number of religious places of users surrounding park \\
\hline & Road density & $\begin{array}{l}\text { The ratio of the length of the total road network to the reachable park area } \\
\text { within a radius of } 400 \mathrm{~m}(\mathrm{~km} / \mathrm{sq} . \mathrm{km})\end{array}$ \\
\hline & Diversity of housing types & Number of types of residential buildings \\
\hline & Building density & Number of buildings per square kilometer \\
\hline & Floor area ratio & The total gross floor area of all buildings within $400 \mathrm{~m}$ from park \\
\hline & Open space ratio & $\begin{array}{l}\text { The open area that is relevant to the building floor area in the form of } \\
\text { a percentage }\end{array}$ \\
\hline & Image of the city & Number of elements of the image of the city (path, edge, node, landmark) \\
\hline \multirow{10}{*}{$\begin{array}{l}\text { Internal } \\
\text { factor } \\
\text { (conditions } \\
\text { at the site) }\end{array}$} & Park use on weekday & $\begin{array}{l}\text { Number of park users on a weekday (square meters of urban park space } \\
\text { per person) }\end{array}$ \\
\hline & Weekend park usage & $\begin{array}{l}\text { Number of park users on weekend (square meters of urban park space } \\
\text { per person) }\end{array}$ \\
\hline & Size of park & The size of the space in the park in square meters \\
\hline & Age of park & Age of the park (2020 subtracted by the year of construction) \\
\hline & Significant history and culture & $\begin{array}{l}\text { Dummy variable that describes significant history and culture; } 1 \text { indicates } \\
\text { significant history and culture, while } 0 \text { means no significant history or culture }\end{array}$ \\
\hline & Recreation facilities provided & $\begin{array}{l}\text { Number of amenities within the urban park (rest area, play areas, sports } \\
\text { activity areas, cultural and recreational centers, and other facilities) }\end{array}$ \\
\hline & Public transport services & $\begin{array}{l}\text { Number of public transport services that reach the park (buses, subways, } \\
\text { and boats) }\end{array}$ \\
\hline & Modes of transportation & Types of transport supporting the accessibility of the park \\
\hline & The critical role of park & $\begin{array}{l}\text { Number of critical roles of the park such as recreation, heritage, health and } \\
\text { wellness, natural environment, education }\end{array}$ \\
\hline & Coverage of blue infrastructure & Percentage of water resource area (i.e., ponds, small lakes) inside the park (in \%) \\
\hline
\end{tabular}




\subsubsection{External Factors}

Accessibility is an important physical factor of a public park that describes it in terms of being reachable by walking within a radius of approximately 0.4 to $0.8 \mathrm{~km}\left(\frac{1}{4}-\frac{1}{2}\right.$ miles). The above-mentioned distance is the suitable range that promotes the use of public parks via nonmotorized transport journeys to parks such as walking and biking [10,51,52]. Therefore, the distance restriction in walking for each public park in this study was limited by a radius of $400 \mathrm{~m}$ in accordance with the goal of the reachable potential of parks by walking as formulated in the Green Bangkok 2030 plan. Nine external factors' values were used for calculations, which are (1) the degree of the land-use mix was obtained from a GIS shapefile format data of the building layers that were classified according to building uses. The classification was compiled by the Department of Public Works and Town \& Country Planning of Thailand (DPT), which include uses of buildings such as residential, commercial activity, mixed-use, manufacturing and processing activity, educational, governmental service, and other purposes [53] to calculate the value of the mixed numbers of building functions. Due to the areas around the public parks having a high number of mixed uses, the number of occupants of buildings varies widely and can therefore provide many potential users to hold activities in the nearby public parks that help to create an important sense of place in different parts of the city $[23,54,55]$. (2) The community components refer to the local social factors. the Thai social context buildings and places provide venues that encourage social interaction in communities, or among specific groups of people, for example, schools, government and religious institutions (e.g., temples) $[56,57]$. (3) The number of religious affiliations of users represents the religious diversity of the surrounding area of the public park. The research used the data collected by DPT which counted the number of temples, churches, mosques, and shrines within the $400 \mathrm{~m}$ radius of the park [53]. Each faith has different daily practices, which results in their promoting a variety of rituals, ceremonies and other religious events at different times of the year $[1,7,33,34]$. (4) Road density is the ratio of the length of the total road network to the walking-distance-reachable park area $(\mathrm{km} / \mathrm{sq}$. $\mathrm{km})$. A higher density indicates that many more roads can be chosen for ease to the park, providing a more convenient road network within the walking distance area [58-60]. (5) The number of types of residential buildings refers to the number of building types, which are classified by DPT into five kinds: detached homes, semi-detached homes, townhouses, condominiums, and others [23,27,53]. (6) Building density is the ratio of the building number per walking-distance-reachable park area, which reflects the urban morphology or the locational functionality of the park to support the needs of the local population within the walking distance area [5,54,61]. (7) Floor area ratio (FAR) is the total gross floor area of all buildings within $400 \mathrm{~m}$ from park that varies directly with the level of urbanization. Additionally, a high FAR ratio reflects the intensity of land development that determines the character of a reachable area of an urban park and the load on public utilities and services [59,62]. (8) Open space ratio (OSR) is the open area in the walking distance reachable area that relates to the building floor area in the form of a percentage. However, the OSR has an inverse variation with FAR that indicates the urban development level; a high OSR ratio reflects a low level of urbanization [59,62]. Nevertheless, the open spaces provide people with many opportunities to gather and engage with the community. If public space utilization is successful, the social space then provides diverse groups of people in our cities places to mingle, interact, and participate in communal activities that helps to develop a strong sense of community identity and pride. (9) The elements of the image of the city are the urban features that support the urban image, reflect the unique characteristics of the area, and encourage the awareness of local experiences and sense of place $[10,22,25,63]$. The elements of the city image are as follows: (i) Paths are pedestrian routes that people use to travel from one place to another. Therefore, people have the chance to experience many parts of the city in their journey and develop an attachment with such as the streets, sidewalks, canals, railroads, and other channels that they used for their journey. (ii) Edge is a factor that delimitates the boundaries including both natural and human-made barriers. (iii) A district is a community that has its 
unique characteristics. The size of each district is different than the others based on these characteristics. Districts are also a part of the city and individuality created by the social structure, lifestyle and architecture. (iv) A node or assembly point is used as a center point, stop-off spot, such as a crowded downtown square. (v) A landmark is a noticeable spot, turning point, or indicator that is particularly visible at both long and short distances [2].

\subsubsection{Internal Factors}

Internal factors are the major factors that define the characteristics of urban parks and are associated with park uses and physical elements within each public park's boundary. These are (1) the number of park users on weekdays and (2) during the weekend. These data were collected for the 2020 by the Office of Public Parks, Department of Environment of Bangkok Metropolitan Administration. The number of park visits outlines the need for equitable and safe access to neighborhood parks and suggests the potential to provide more variety of park uses in the study area [33]. Park services meet high demand of park users is adequate when the spatial distribution of urban population is in harmony with parks, that is, whether densely or sparsely populated areas in city, residents' demands can be satisfied with suitable parks provision. (3) The size of the park reflects the carrying capacity of the park including its recreational facilities in supporting the park usage $[22,33,58]$. (4) The age of park reflects the period of each park's existence. (5) Significant historical park's cultural history that is represented by the park site includes cultural landscapes, historic structures, and archeological resources that enhanced in value by design that is unique in beauty reflecting the historic of the park establishment. This creates the attractiveness of the park for any passers-by $[7,8,25,26]$. Parks in Bangkok have primarily been supported through two means: donations from important persons, such as the monarchy or nobility, and land donation by the government [41]. (6) The provided facilities element refers to the number of facilities within each park. It is said that a good public space must be equipped with convenient and sufficient facilities for supporting all genders and different age groups $[7,22,25,26,64]$. (7) Public transportation service to the parks reflects the public transportation service availability such as buses, river boats, and rapid metropolitan trains. Parks that have good connections with public transportation to a large extent always have a high accessibility potential $[57,60,61]$. (8) Mode of transportation represents the type of public transportation that can be used for traveling to each park. A variety of transportation reflects the within-reach-potential of the park; thus, a high number of transportation types leads to higher reachable potential of the park $[18,58,60]$. (9) The critical roles of a park refer to the particular types of park usage for which the park has been designed. A wide range of activities increases the potential to attract a variety of users. Moreover, this can encourage more social interaction among park visitors and users $[22,27,35,64]$. The public areas in Thailand have provided places for many kinds of activities, for example, recreation, social interaction, religious rituals, learning and education, exchange and trade, transportation and accessibility, landmarks, and political engagement $[8,9,20]$. (10) The coverage of blue infrastructure is a natural ecosystem factor including aquatic areas such as ponds, rivers, and canals that have been created by nature or humans to imitate the natural environment $[54,56,65]$. In the park studied in this research, green infrastructure or green spaces of trees and grasses are found in every park. Water resources in the parks support the existence of an ecosystem that adds to the natural environment in these public parks. Unfortunately, such natural resources are rarely taken into account in Bangkok park design.

\subsection{Factor Analysis and Urban Park Classification}

The second stage of the multi-step statistical analysis was applied to develop the multi-dimensional classification of urban parks in Bangkok reflecting their unique internal and external characteristics. First, values for all computed variables were normalized in this research before performing the variable classification analysis. The grouping was based on the principal component analysis (PCA) by applying the Kaiser normalization varimax rotation $[66,67]$. However, the variables that were not used in the classification 
analysis were the ones with coefficients lower than $0.5[67,68]$. The above sorting is a new set of correlated factors (principal components) and was used as the important variables in the process of studying urban public park classification by the K-means cluster analysis. The analysis is a public park classification to group the parks that share similar factors and separate the parks that have different factors [69]. Therefore, the elbow method was selected to determine the public park's optimal number of clusters [70]. The hierarchical clustering with Ward's linkage was chosen to determine the number of clusters in the analysis by using all the data. Second, the hierarchical clustering technique can be visualized by using a dendrogram as a tree diagram where the urban parks that were viewed as most similar by the external and internal factors in the study are closely placed on branches together. Finally, the public park classification result was input to the GIS to display a map of the location distribution of each public park group in the study area.

\section{Results}

\subsection{Identifying the Influencing Factors}

The result of both external and internal factor analysis found that all 19 subfactors that influence the public park use can be classified into six groups of new factors. Additionally, each factor is relevant to one another as shown by the factor loading values presented in Table 3. Each principal component (PC) has a similar relationship reflected in the demonstrative character of the factors. For further illustration, the researchers named each factor classification as follows: (1) The building and land-use factor (PC1), which was a combination of four external factors that indicate the level of urbanization density and intensity, for example, the diversity of housing types, OSR, building density, and FAR. (2) The usage factor (PC2) is a factor that reflects the number of park users on weekdays and weekends, which is relevant to the age and size of the park. (3) The accessibility factor (PC3) mostly consists of the combination of the public transport services, significant historical and cultural sites, the critical role of the park, and modes of transportation that are connected with the walking distance area around the park. (4) The man-made infrastructure factor (PC4) refers to the road and water resource structures. (5) The social and cultural factor (PC5) is the combination of two external factors, namely, the degree of the land-use mix and the community component. This illustrates the context of the community in Thailand and its mixed type of land use and settlements close to religious places at the local center. (6) The image of the city factor (PC6) is the factor combination in the urban landscape elements that individually represents the city's identity.

Table 3. Factor loadings based on a principal component analysis with varimax rotation.

\begin{tabular}{ccccccc}
\hline Variables & \multicolumn{7}{c}{ Factor Loadings } \\
\cline { 2 - 7 } & $\mathbf{P C 1}$ & $\mathbf{P C 2}$ & $\mathbf{P C 3}$ & PC4 & PC5 & PC6 \\
\hline Diversity of housing types & $\mathbf{0 . 9 2 4}$ & -0.008 & -0.030 & -0.009 & 0.048 & -0.224 \\
OSR & $\mathbf{- 0 . 9 2 4}$ & -0.220 & -0.168 & -0.095 & -0.001 & -0.032 \\
Building density & $\mathbf{0 . 8 6 2}$ & 0.033 & -0.229 & 0.163 & 0.132 & 0.158 \\
FAR & $\mathbf{0 . 8 1 9}$ & 0.113 & 0.304 & 0.131 & -0.037 & -0.021 \\
Park use on weekday & 0.132 & $\mathbf{0 . 9 0 5}$ & 0.207 & -0.125 & 0.005 & -0.096 \\
Weekend park usage & 0.115 & $\mathbf{0 . 9 1 4}$ & 0.216 & -0.086 & -0.049 & -0.034 \\
Size of park & -0.046 & $\mathbf{0 . 8 2 1}$ & 0.174 & 0.166 & -0.352 & -0.123 \\
Age of park & 0.271 & $\mathbf{0 . 6 0 5}$ & 0.376 & -0.061 & 0.276 & 0.073 \\
Public transport services & -0.224 & 0.339 & $\mathbf{0 . 7 9 2}$ & 0.113 & 0.132 & 0.040 \\
Significant historical and cultural & 0.239 & 0.178 & $\mathbf{0 . 7 5 4}$ & 0.098 & 0.060 & -0.091 \\
Critical role of park & 0.095 & 0.125 & $\mathbf{0 . 7 3 1}$ & -0.064 & -0.295 & -0.194 \\
Modes of transportation & -0.020 & 0.376 & $\mathbf{0 . 6 0 1}$ & -0.347 & 0.128 & 0.131 \\
Coverage of blue infrastructure & 0.145 & -0.335 & 0.025 & $\mathbf{0 . 7 7 6}$ & -0.184 & -0.045 \\
Road density & 0.187 & 0.172 & 0.029 & $\mathbf{0 . 7 3 5}$ & 0.238 & 0.016 \\
Degree of land-use mixture & 0.223 & -0.026 & 0.157 & 0.242 & $\mathbf{0 . 8 0 2}$ & -0.062 \\
Community component & -0.154 & -0.168 & -0.274 & -0.423 & $\mathbf{0 . 6 9 0}$ & 0.207 \\
Image of the city & -0.197 & -0.087 & 0.067 & 0.063 & 0.243 & $\mathbf{0 . 7 8 7}$ \\
Religious diversity & 0.266 & 0.013 & -0.151 & -0.176 & -0.224 & $\mathbf{0 . 7 0 5}$ \\
Facilities element provided & 0.240 & 0.369 & 0.298 & -0.413 & -0.060 & $-\mathbf{0 . 4 6 7}$ \\
\hline
\end{tabular}

Note. Numbers in bold represent the highest loading of each variable on one factor. 


\subsection{Classification of the Typology of Urban Public Parks and Their Characteristics}

The cluster analysis outcome was used for the typology classification of 30 urban public parks. In other words, the parks were sorted into groups that share similar factors to other groups. By applying the elbow method, six proper groups were found with different influencing factors on Bangkok public park utilization as indicated by the dendrogram of Figure 3. Moreover, the classification result is presented on the map (Figure 4) to display the spatial distribution of each public park in Bangkok. Thus, after considering the urbanization zone division of Bangkok, 14 public parks were found in cluster 2, which is equal to 47 percent of the total studied parks. They are spread over three zones, which are the inner, the middle, and the outer zone. The two parks each of cluster 1 and cluster 5 are bunched together in the inner zone only, in contrast to the parks in cluster 3 and cluster 6 , which were not found in the outer zone or the outskirts of Bangkok. In summary, judging by the size of members in each group, the highest number of group members was found in cluster 2, which is 14 parks or $46.67 \%$, while cluster 3 had $20.00 \%$, and cluster 4 had $13.33 \%$. Cluster 1, cluster 5, and cluster 6 had two parks each as presented in Figure 4.
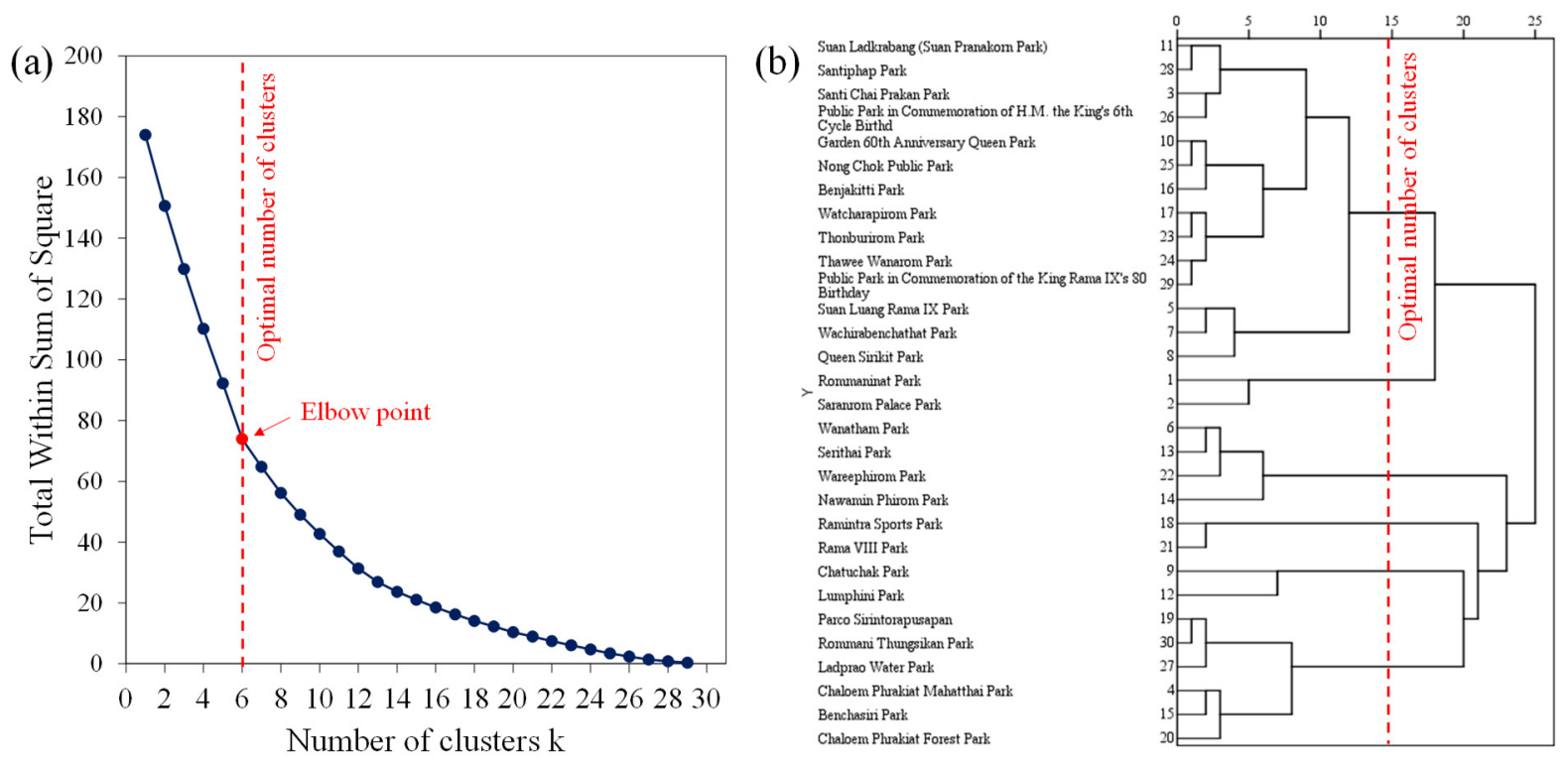

Figure 3. (a) Using the elbow method to determine the optimal number of clusters, and (b) dendrogram of hierarchical clustering by Ward's method with Euclidean distance.

According to the consideration of the factors that influenced the public urban parks in Bangkok presented in Figure 5 and Table 4, cluster 1 was named in this research as the "Historical Parks" and is one of the three clusters with the fewest group members, two parks or $6.67 \%$, specifically Rommaninat Park and Saranrom Palace Park, which are located in the inner zone of BMA. They are located opposite the Grand Royal Palace to the east. This zone was once a downtown area and had a high density of land use. They are also the prime historical parks due to their highest historical and cultural value, compared to other groups. Rommaninat Park is a new community park, a royal offering to Her Majesty Queen Sirikit, the Queen Mother on the occasion of her 60th birthday celebration in 1992, while Saranrom Palace Park has been the royal park of Saranrom Palace that His Majesty King Chomklao graciously requested to be built in 1866 . Therefore, the palace was built at the beginning of his reign, which was around the year 1874 as per the suggestion of Henry Alabaster, the botanical garden designer who designed the royal park in the international style. The architecture in the royal park is approximately 150 years old, a high historical value because they were built in the reign of King Rama IV. Moreover, the park is not only a historical place and an area for community activities, but it also endows the city with a pleasing urban scenery that attracts passers. Nowadays, the above-mentioned area is crowded with 
residential communities and government offices, whose outstanding buildings have high historical and heritage values. A variety of public transportation facilities are available in this area, including buses, subways, and boats providing convenient connections to other important places in the city.

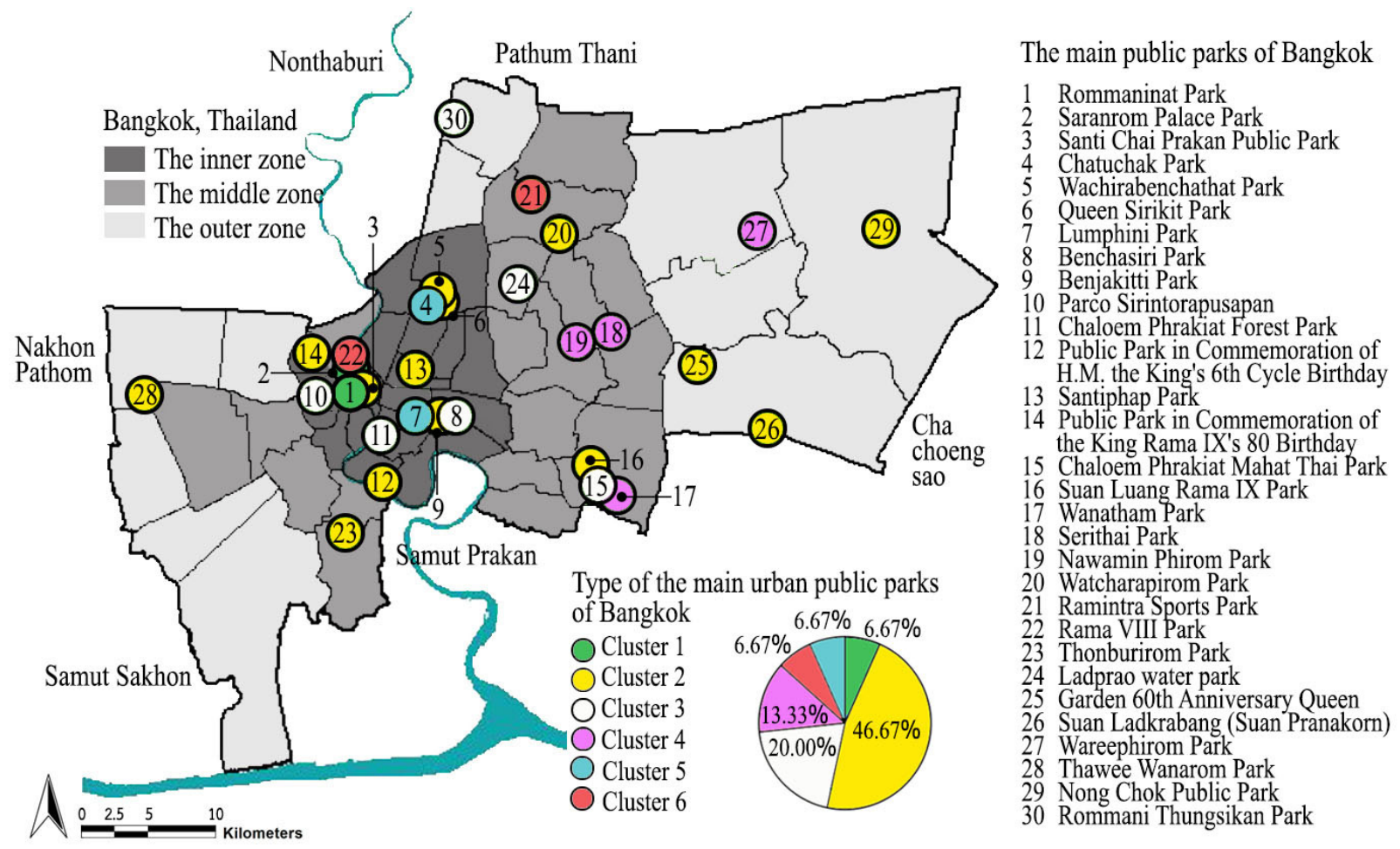

Figure 4. Locations of the 30 main urban public parks in Bangkok, classified into six clusters.
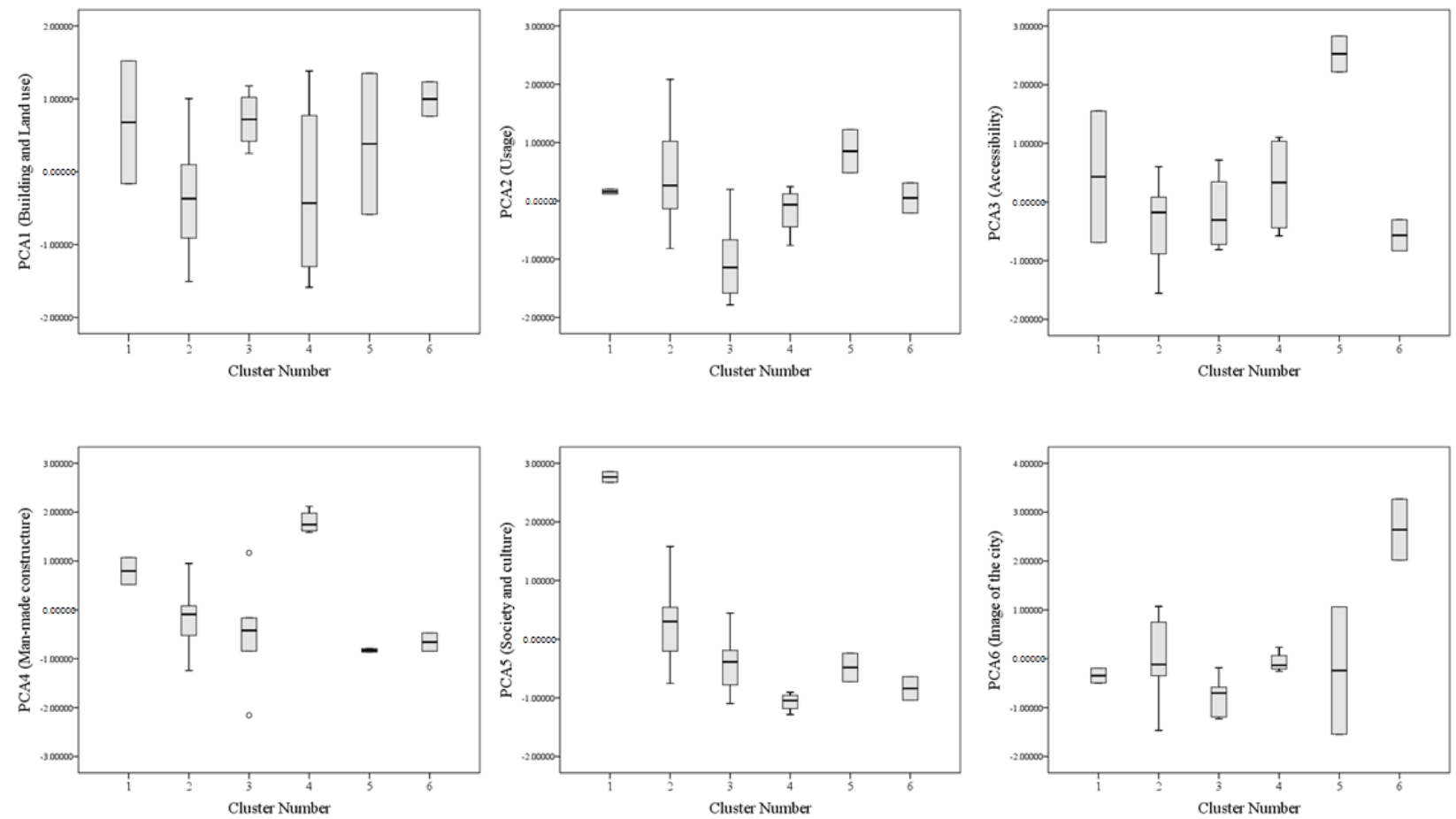

Figure 5. The correlation between the factors and the clusters of urban public parks in BMA. 
Table 4. The characteristics of a sample of urban public park types in Bangkok.

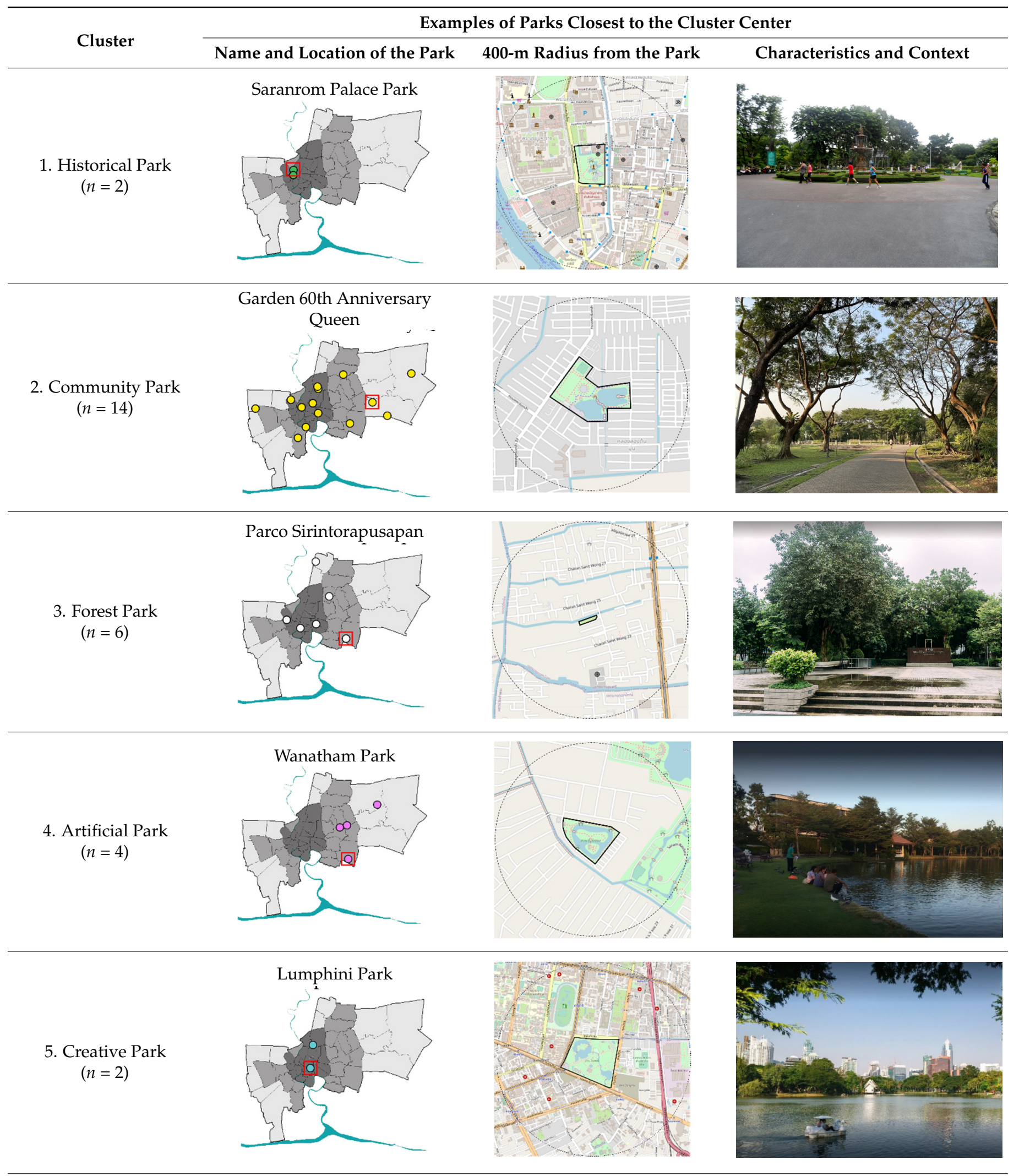


Table 4. Cont

\begin{tabular}{lll}
\hline \multirow{2}{*}{ Cluster } & \multicolumn{3}{c}{ Examples of Parks Closest to the Cluster Center } \\
\cline { 2 - 4 } & Name and Location of the Park 400-m Radius from the Park Characteristics and Context \\
\hline & 6. Appreciated Park \\
$(n=2)$
\end{tabular}

Cluster 2 is the group with the highest number of members, 14 parks or $46.67 \%$, which include Benjakitti Park, Garden 60th Anniversary Queen Park, Nong Chok Public Park, Public Park in Commemoration of H.M. the King's 6th Cycle Birthday, Public Park in Commemoration of King Rama IX's 80 Birthday, Queen Sirikit Park, Santi Chai Prakan Park, Santiphap Park, Suan Ladkrabang (Suan Pranakorn Park), Suan Luang Rama IX Park, Thawee Wanarom Park, Thonburirom Park, Wachirabenchathat Park, and Watcharapirom Park. The locations of the parks in this group are spread over three zones of Bangkok. Moreover, they share a similar high value in the usage factor, although their values of accessibility factor and building and land-use factor are quite low compared to other groups. Therefore, the examination of the physical characteristics of their locations and their relationship with the factors show that this Cluster 2 is among the low urbanization communities that have a low density of buildings and population. There are also a few recreation and leisure facilities. The areas around the parks are also poor accessibility to park with lowest road density. In contrast, they have the potential to support the park usage of local people for access by private vehicles. The defining characteristic of parks in this group is a wide assortment of recreational facilities attracts more visitors within a large park size than other parks. This is the main reason that the parks in this group are called the "Community Parks" such as Garden 60th Anniversary Queen Park, which is a member of this cluster that is located in the outer zone. This is a huge park with a lot of open spaces but fewer buildings around the park. Inside the park, the landscape is full of natural elements, especially the water resources in the form of a huge pond and big trees that comprise the elements of green-blue infrastructure. Moreover, it is equipped with convenient facilities for all kinds of usage, including relaxation in both active and passive activities. Overall, parks in this group play an important role as suburban public open spaces that can support any mass activities for the local districts and nearby communities.

Cluster 3 has the second-highest number of members, six parks or 20 percent of all studied parks. This includes Benchasiri Park, Chaloem Prakiat Forest Park, Chaioem Prakiat Mahatthai Park, Ladprao Water Park, Parco Sirintorapusapan, and Romani Thungsikan Park. Most of these parks are located throughout the inner and middle zones of Bangkok, with high average value for building and land-use factors, while the average values of usage, social and culture, and image of the city factors are at the lowest level in comparison to other groups. However, after considering the physical context of the location and the relationship with the potential factors influencing the park service area, the size of these parks leads to a high ratio of space to users. These large parks have a high potential to boost the value and beauty of the environment by their location alone. Therefore, they are named as the "Forest Parks", such as Parco Sirintorapusapan Park. This example of this cluster is located in the city center where the buildings and population densities are high. Moreover, inside the park, the green zone, which is full of trees of varying sizes, is an open space for fresh air and exercise. Additionally, these parks can support relaxing after-work activities for the residents and those who are in the walking distance area. 
Cluster 4 has the third-highest number of members, four parks or 13.33 percent. This includes Nawamin Phirom Park, Serithai Park, Wanatham Park, and Wareephirom Park. This cluster is mostly located in the middle and outer zones of Bangkok with the highest average value of man-made infrastructure factor as the outstanding characteristic. On the other hand, the value of the relationship between usage and social and cultural factors is the lowest, especially the usage factor, which has the lowest value of all main factors among all public park groups. Even though the parks in this group are located outside the city and have less expansion in their usage than other park groups, they have been beautifully created with man-made landscapes that can provide gorgeous and outstanding scenery and environment making them landmarks of the city outskirts. Therefore, this cluster is referred to as the "Artificial Parks", such as Wanatham Park, a park of this group that is surrounded by an area of a low residential density with a low-rise residential area near Suvarnabhumi Airport. One potential concern is that the low-density character of the neighborhoods around these parks may limit park demand, particularly given that single-family homes tend to have private green spaces (i.e., yards and patio areas), thus reducing reliance on public parks. Wanatham Park was designed with a remarkable layout plan and internal composition, which can improve the surrounding scenery of the monotonous suburban sprawl of residential developments and highways while at the same time providing open spaces for physical and entertainment activities for the local population.

Cluster 5 is one of the three groups that have the fewest members, 6.67 percent, which are two parks, namely, Chatuchak Park and Lumphini Park. Both parks are located in the inner zone of BMA, which is the center for a variety of people and diverse social and economic land uses. These parks are in the heart of Bangkok main traffic routes. Both parks represent huge nodes for residents to gather and relax, and in the case of Chatuchak Park located to major transportation terminals, for travelers as well, who come in and out of Bangkok. The areas around the perimeter of both parks are well known transit-oriented development (TOD) districts [36,44].

Moreover, the spatial context of both Cluster 5 parks is strongly related to the accessibility and usage factors compared to other groups of public parks. Because the parks are located in the central business district of Bangkok with high densities of both buildings and population and serviced by a convenient mass transit system that can facilitate many groups of people from farther areas to access these public parks, they generate much more variety in colorful and lively activities. For this reason, this park group is named the "Creative Parks". Lumphini Park, a large public open space surrounded by tall buildings in the heart of the city characterized by packed crowds on weekdays and even more during weekends. Moreover, these parks are reachable through many traffic routes, especially Sala Daeng Station on the BTS Skytrain's Silom Line as well as Lumphini and Si Lom stations on the MRT Blue Line and other public transportation. Thus, Lumphini Park has become a popular space for every group of people to use. A variety of activities can also be found in the park (e.g., recreation boating, children's playground, youth center for swimming, soccer, basketball, dancing, library, biking, body building) which is supported by the provision of a wide range of facilities.

Cluster 6 has the smallest number of members, two parks, equal to cluster 1 and 5, specifically Rama VIII Park and Ramintra Sports Park, which are located in the inner and middle zones of Bangkok. They are remarkable due to the image of the city, and building and land-use factors have the highest average values among all park groups. In contrast, the average value of the accessibility factor is significantly lower than other groups. Because the parks are located in the middle of communities that have high densities of both buildings and population, they have been designed to have beautiful surroundings to promote local aesthetics. Therefore, this park group is given the name of "Appreciated Parks". It is exemplified by the elegant Rama VIII Park, located on the western shore of Chao Praya River where the towering Rama VIII Bridge, a striking single-pole cable-stayed bridge over Chao Praya River, can be seen from the park. Overall, the park has been used as a relaxing area for western Bangkok residents. 


\section{Discussion}

In this study, multi-dimensional clustering approaches were employed to classify complex urban elements in a way that facilitates understanding, discussion, and analysis, specifically, the typology of parks and their location. Such knowledge is necessary for meaningful, geographically contextualized planning and management of urban parks. Some limitations have been found in the multi-dimensional clustering analysis, which may affect the accuracy of data analysis in classifying urban parks. This is due mainly to the application of secondary data, which came from the government's open data base as the main information source for this research. The integration of additional data (e.g., future development, environmentally sensitive areas, flood hazard, biodiversity areas, social environments) can provide a more significant comprehensive investigation, although studies with limited data (e.g., basic social and park data) can still offer valuable insight into the composition and distribution of a city park system [54,71,72]. It can therefore be suggested for any future study that the data from the field survey, which includes both characteristics of the usage and behavior of the users, should be integrated with an indepth analysis of both spatial and physical characteristics through surveys, questionnaires of actual usage, field evaluations of individual parks, and other qualitative research methods [73-75]. By applying a mixed-methods research approach to investigate the multiple dimensions of complex urban park systems, the full potential of these often underappreciated spaces and places can be harnessed so that they may become transformative drivers of change in the quest for improving quality of life and sustainability of cities.

Moreover, the park grouping in this study did not cover the analysis of the socioeconomic status of the urban public park users that determines variability in their usage. Nevertheless, the results did prioritize strategic interventions, highlighting the next step of informing suitable park policy, planning, and management. In summary, future research in this vein should strive to refine the approach presented here continually, augmenting such large-scale quantitative assessments with field evaluations of individual parks, community surveys, and other qualitative research methods.

\section{Conclusions}

This research presents a method of multi-dimensional clustering that was applied to classify the typology of urban public parks along with 19 external and internal factors in total that influence the usage of the city public parks in Bangkok. A total of 30 public parks were included in this study. The parks have been subject of a landscape design renovation plan as per the policy of Green Bangkok 2030. The findings of this study will be of practical value when designing parks or undertaking city planning in the future. The outcome of this research can be used for the classification of public parks, which is based primarily on the similarity of the parks' spatial context and physical characteristics sorted out into six clusters in total: historical parks, community parks, forest parks, artificial parks, creative parks, and appreciated parks. To illustrate this, all kinds of parks have a statistically significant relationship with the physical and social contexts in the particular surrounding areas. The most common park type in Bangkok is the community park. The defining characteristics of these parks are that they are small and located in the least densely populated neighborhoods. The combination of single-family dwellings and lowrise residential occupancies was unexpected but may be explained by the absence of other land uses around these parks and the overall dominance of low-density developments and single-family homes in Bangkok. According to the Green Bangkok 2030 policy, which defined increase in the green spaces to 10 square meters per person, these parks may be under pressure of overuse problems for their high park congestion. Most of these parks were community parks, which were located in a suburban area of Bangkok. Their service areas were relatively small, which means high demands of park were needed by nearby residents. Therefore, we suggest that Bangkok's policy makers take measures to release the pressure on these kinds of parks, such as building small community parks within their service areas. 
Furthermore, this study found two important aspects for understanding urban public park development. These are (i) the spatial issue, which is a physical environmental characteristic of the parks in the research area that varies depending on the level of urbanization and urban structure development level. It can be said that parks that are located in the area of high urbanization or the inner zone are provided with convenient public mass transportation and designed to support the park usage or activities. They have a greater variety of uses than the public parks that are located in the middle and outer zones of Bangkok. On the other hand, the parks that are located in a low urbanization area usually have a larger size than the downtown parks as well as a more natural composition than the central parks perhaps with the exception of the huge Lumphini Park which was allocated in the time of Rama V. (ii) The second aspect is the issue of methodology that integrates the outer factors within a radius of $400 \mathrm{~m}$ of the park location with the inner factors or the data of park usage and physical composition to understand the park characteristics in its spatial context. The public functions of parks should be better considered in the design process to meet the increasingly diverse needs of the people. If a public park is designed to serve a diverse range of citizens, multiple functions and attractive themes are needed to broaden its appeal to users. People are willing to visit more distant parks for special features such as historical value, cultural themes, or natural landscapes [76-78]. Therefore, the results from each park analysis will be useful for decision making, park planning and management in urban areas.

Author Contributions: Conceptualization, C.K. and M.S.; methodology, M.S.; software, M.S. and C.K.; writing-original draft preparation, C.K. and M.S.; writing-review and editing, C.K. and M.S.; visualization, C.K.; supervision, M.S. All authors have read and agreed to the published version of the manuscript.

Funding: This research did not receive any specific grant from any public or commercial funding agencies or any nonprofit sectors.

Institutional Review Board Statement: Not applicable.

Informed Consent Statement: Not applicable.

Data Availability Statement: Data sharing not applicable.

Acknowledgments: The authors appreciate the Bangkok Metropolitan Administration for sharing their data and supporting this study.

Conflicts of Interest: The authors declare no conflict of interest.

\section{References}

1. Jacobs, J. The Death and Life of Great American Cities; Random House: New York, NY, USA, 1961; pp. 89-112.

2. Lynch, K. A Theory of Good City Form; The MIT Press: London, UK, 1981; pp. 293-318.

3. Mumford, L. The Cultures of Cities; Harcourt Brace Jovanovich: New York, NY, USA, 1970; pp. 51-58.

4. Mensch, J. Public Space: Continental Philosophy Review; Springer Nature Switzerland AG: Cham, Switzerland, 2007; Volume 40, pp. 31-47.

5. Olanescu, O.S.; Agachi, M.I. Public Space as a Sustainable Built Environment Feature. Acta Tech. Napoc. Civ. Eng. Archit. 2015, 58, 154-159.

6. Loures, L.; Santos, R.; Panagopoulos, T. Urban parks and sustainable city planning-The case of Portimão, Portugal. WSEAS Trans. Environ. Dev. 2007, 3, 171-180.

7. Marcus, C.; Francis, C. PEOPLE PLACES: Design Guidelines for Urban Open Space, 2nd ed.; John Willey \& Sons: New York, NY, USA, 1998; pp. 85-89.

8. Madanipour, A. WHOSE PUBLIC SPACE? International Case Studies in Urban Design and Development; Routledge: New York, NY, USA, 2010; pp. 49-55.

9. Kongphunphin, C.; Iamtrakul, P. Roles of Public Spaces in Transition: Case Study of Thailand. J. Fac. Archit. King Monkut's Inst. Technol. Ladkrabang 2019, 26, 30-40.

10. Carmona, M.; Tiesdell, S.; Heath, T.; Oc, T. Public Places-Urban Spaces: The Dimensions of Urban Design, 2nd.; Architectural Press: Burlington, MA, USA, 2010; pp. 89-95.

11. Bolund, P.; Hunhammar, S. Ecosystem services in urban areas. Ecol. Econ. 1999, 29, 293-301. [CrossRef]

12. Crane, P.; Kinzig, A. Nature in the metropolis. Sci. Am. Assoc. Adv. Sci. 2005, 308, 1225-1226. [CrossRef] 
13. Gaston, K.J.; Warren, P.H.; Thompson, K.; Smith, R.M. Urban domestic gardens (IV): The Extent of the Resource and its Associated Features. Biodivers. Conserv. 2005, 14, 3327-3349. [CrossRef]

14. Smith, R.M.; Gaston, K.J.; Warren, P.H.; Thompson, K. Urban domestic gardens (V): Relationships between landcover composition, housing and landscape. Landsc. Ecol. 2005, 20, 235-253. [CrossRef]

15. Panagopoulos, T. Using Microclimatic Landscape Design to Create Thermal Comfort and Energy Efficiency. Actas da 1a Conferencia sobre Edificios Eficientes Universidade do Algarve 2008, 25, 1-4.

16. Twohig-Bennett, C.; Jones, A. The health benefits of great outdoors: A systematic review and meta-analysis of greenspace exposure and health outcomes. Environ. Res Natl. Libr. Med. 2018, 166, 628-637. [CrossRef] [PubMed]

17. Amani-Beni, M.; Zhang, B.; Xie, G.; Xu, J. Impact of urban park's tree, grass and waterbody on microclimate in hot summer days: A case study of Olympic Park in Beijing, China. Urban For. Urban Green. 2018, 32, 1-6. [CrossRef]

18. Transforming Our World: The 2030 Agenda for Sustainable Development. Available online: http://www.un.org/ga/search/ view_doc.asp?symbol=A/RES/70/1\&Lang=E (accessed on 26 August 2020).

19. Wu, J.; Plantinga, A.J. The influence of public open space on urban spatial structure. J. Environ. Econ. Manag. 2003, 46, 288-309. [CrossRef]

20. Placemaking with Project for Public Spaces. Available online: https://www.pps.org/pdf/pps_brochure.pdf (accessed on 24 August 2020).

21. Oliveira, V. Urban Morphology: An Introduction to the Study of the Physical Form of Cities; Springer International Publishing: Cham, Switzerland, 2016; pp. 142-145.

22. Brown, G.; Schebella, M.F.; Weber, D. Using participatory GIS to measure physical activity and urban benefits. Landsc. Urban Plan 2014, 121, 34-44. [CrossRef]

23. Donahue, M.L.; Keeler, B.L.; Wood, S.A.; Fisher, D.M.; Hamstead, Z.A.; McPlearson, T. Using social media to understand drivers of urban park visitation in the Twin Cities, MN. Landsc. Urban Plan. 2018, 175, 1-10. [CrossRef]

24. Koohsari, M.J.; Mavoa, S.; Villanueva, K.; Sugiyama, T.; Badland, H.; Kaczynski, A.T.; Owen, N.; Giles-Corti, B. Public open space, physical activity, urban design and public health: Concepts, methods and research agenda. Health Place 2015, $33,75-82$. [CrossRef]

25. Carr, S.; Francis, M.; Rivilin, L.G.; Stone, A.M. Public space; Cambridge University Press: New York, NY, USA, $1992 ;$ pp. $232-236$.

26. Whyte, W.H. The Social Life of Small Urban Spaces; Project for Public Spaces: New York, NY, USA, 2001; pp. 66-79.

27. Mowen, A.; Orsega-Smith, E.; Payne, L.; Ainsworth, B.; Godbey, G. The role of park proximity and social support in shaping park visitation, physical activity, and perceived health among older adults. J. Phys. Act. Health 2007, 2, 167-179. [CrossRef] [PubMed]

28. Ye, Y.; Nes, A.V. Quantitative tools in urban morphology: Combining space syntax, Spacematrix, and Mixed-use Index in a GIS framework. Urban Morphol. 2014, 18, 97-118.

29. Open Space Strategies: Best Practice Guidance. Available online: https://www.designcouncil.org.uk/sites/default/files/asset/ document/open-space-strategies.pdf (accessed on 19 April 2021).

30. Choi, H.S. How are public spaces sustaining cultural identities in the context of China' s increasingly globally focused urban developments: Using a case study of Putuo in Shanghai. J. Archit. Urban. 2016, 40, 198-205. [CrossRef]

31. Zucker, P. Town and Square: From the Agora to Village Green; Columbia University Press: New York, NY, USA, 1959 ; pp. $142-145$.

32. Gehl, J. Life Between Buildings; Van Nostrand Reinhold: New York, NY, USA, 1987; pp. 49-53.

33. Hume City Council. Open Space Strategy 2010-2015; Hume City Council: Victoria, Australia, 2003; pp. 50-62.

34. Basri, B.H. Valuing the Attributes of Malaysian Recreational Parks: A Choice Experiment Approach. Ph.D. Thesis, School of Agriculture, Food and Rural Development, Newcastle University, Newcastle, UK, June 2011.

35. Department of Sport and Recreation. Classification Framework for Public Open Space; Department of Sport and Recreation: Perth, Australia, 2013; pp. 5-8.

36. Kongphunphin, C.; Iamtrakul, P.; Srivanit, M. The attitude in Urban Planning of Thai Urban Public Space. Int. J. Build. Urban Inter. Landsc. Technol. 2018, 12, 59-74.

37. Van Herzele, A.; Wiedemann, T. A monitoring tool for the provision of accessible and attractive urban green spaces. Landsc. Urban Plan. 2003, 63, 109-126. [CrossRef]

38. Bedimo-Rung, A.L.; Mowen, A.J.; Cohen, D.A. The significance of parks to physical activity and public health: A conceptual model. Am. J. Prev. Med. 2005, 28, 159-168. [CrossRef]

39. Giles-Corti, B.; Timperio, A.; Bull, F.; Pikora, T. Understanding physical activity environmental correlates: Increased specificity for ecological models. Exerc. Sport Sci. Rev. 2005, 33, 175-181. [CrossRef]

40. The Bangkok Comprehensive Plan. Available online: http://cpd.bangkok.go.th:90/web2/kitja56/kitja56 (accessed on 5 March 2021).

41. Office of Public Park, Department of Environment, Bangkok Metropolitan Administration. Report on the implementation of the Annual Work Plan for Bangkok. Available online: http:/ / office.bangkok.go.th/publicpark/index.asp (accessed on 16 September 2020).

42. The New Urban Agenda for Achieving Sustainable Urbanization in Thailand. United Nations Human Settlements Programme. Available online: https:/ / unhabitat.org/es/node/142441 (accessed on 9 April 2021).

43. Statistical Profile of Bangkok Metropolitan Administration. Strategy and Evaluation Department of Bangkok Metropolitan Administration. Available online: http:/ / www.bangkok.go.th/pipd (accessed on 24 April 2021). 
44. Kongphunphin, C.; Srivanit, M. Public spaces in Bangkok and the factors affecting the good public space quality in urban areas. IOP Conf. Ser. Mater. Sci. Engineering 2020, 910, 012024. [CrossRef]

45. Report of the Main Parks in Bangkok. Available online: http://203.155.220.118/green-parks-admin (accessed on 19 April 2021).

46. Evenson, K.R.; Jones, S.A.; Holliday, K.M.; Cohen, D.A.; Mckenzie, T.L. Park characteristics, use, and physical activity: A review of studies using SOPARC (system for observing play and recreation in communities). Prev. Med. 2016, 86, 153-166. [CrossRef]

47. Goličnik, B.; Thompson, C.W. Emerging relationships between design and use of urban park spaces. Landsc. Urban Plan. 2010, 94, 38-53. [CrossRef]

48. Schipperijn, J.; Bentsen, P.; Troelsen, J.; Toftager, M.; Stigsdotter, U.K. Associations between physical activity and characteristics of urban green space. Urban For. Urban Green. 2013, 12, 109-116. [CrossRef]

49. Hillsdon, M.; Panter, J.; Foster, C.; Jones, A. The relationship between access and quality of urban green space with population physical activity. Public Health 2006, 120, 1127. [CrossRef]

50. Li, F.; Zhang, F.; Li, X.; Wang, P.; Liang, J.; Mei, Y.; Cheng, W.; Qian, Y. Spatiotemporal patterns of the use of urban green spaces and external factors contributing to their use in central Beijing. Int. J. Environ. Res. Public Health 2017, 14, 237. [CrossRef] [PubMed]

51. Mertes, J.D.; Hall, J.R. Park, Recreation, Open Space and Greenway Guidelines; Urban Land: Arlington, VA, USA, 1996; pp. 155-163.

52. Brander, L.M.; Koetse, M.J. The value of urban open space: Meta-analyses of contingent valuation and hedonic pricing results. J. Environ. Manag 2011, 92, 2763-2773. [CrossRef]

53. Annual report of Department of Public Works and Town \& Country Planning of BMA. Available online: http://www.bangkok. go.th/upload/user/00000354/plan/reportyear/AR2563.pdf (accessed on 15 April 2021).

54. Ibes, D.C. A multi-dimensional classification and equity analysis of an urban park system: A novel methodology and case study application. Landsc. Urban Plan. 2015, 137, 122-137. [CrossRef]

55. Ye, Y.; Nes, A.V.A. Measuring urban maturation processes in Dutch and Chinese new towns: Combining street network configuration with building density and degree of land use diversification through GIS. J. Space Syntax. 2013, 4, 17-37.

56. Chrysoulakis, N.; Feigenwinter, C.; Triantakonstantis, D.; Penyevskiy, I.; Tal, A.; Parlow, E.; Fleishman, G.; Duzgun, S.; Esch, T.; Marconcini, M. A Conceptual List of Indicators for Urban Planning and Management Based on Earth Observation. Int. J. Geo-Inf. 2014, 3, 908-1002. [CrossRef]

57. What Makes A Successful Place? Available online: https://www.pps.org/article/grplacefeat (accessed on 29 May 2021).

58. Kaczynski, A.T.; Potwarka, L.R.; Saelens, E.B. Association of Park Size, Distance, and Features with Physical Activity in Neighborhood Parks. Am. J. Public Health 2008, 98, 1451-1456. [CrossRef] [PubMed]

59. Sallis, J.F.; Glanz, K. The Role of Built Environments in Physical Activity, Eating, and Obesity in Childhood. Future Child. 2006, 16, 89-108. [CrossRef] [PubMed]

60. Zhang, R.; Wulff, H.; Duan, Y.; Wagner, P. Associations between the physical environment and park-based physical activity: A systematic review. J. Sport Health Sci. 2019, 8, 412-421. [CrossRef]

61. Marshall, S.; Caliskan, O. A joint framework for urban morphology and design. Built Environ. 2011, 37, 409-426. [CrossRef]

62. Urban Indicators for Managing Cities. Available online: https://www.adb.org/sites/default/files/publication/30020/urbanindicators-managing-cities.pdf (accessed on 15 June 2020).

63. Lynch, K. The Image of the City; The MIT Press: London, UK, 1960; pp. 46-48.

64. Lee, S.; Yang, G.; Pei, T.; Ma, T.; Song, C.; Shu, H.; Du, Y.; Zhou, C. Analysis of factors affecting urban park service area in Beijing: Perspectives from multi-source geographic data. Landsc. Urban Plan. 2019, 181, 103-117. [CrossRef]

65. Chan, C.S.; Marafa, L.M. Components of urban park systems: United States and Hong Kong. Parks Recreat. 2006, 41, 26-30.

66. Burns, R.B.; Burns, R.A. Business Research Methods and Statistics Using SPSS; Sage Publishing: Los Angeles, CA, USA, 2008; pp. $145-149$.

67. Matsunaga, M. How to factor-analyze your data right: Do's, don'ts, and how-to's. Int. J. Psychol. Res. 2010, 3, 97-110. [CrossRef]

68. Srivanit, M.; Auttarat, S. Classifying Spatial Homogeneity of Thermally-Stabilized Surface to Define Differentiation Local Atmospheric Zones in Chiang Mai City. J. Archit. Plan. Res. Studies. 2016, 13, 1-21.

69. Rapkin, B.D.; Luke, D.A. Cluster analysis in community research: Epistemology and practice. Am. J. Community Psychol. 1993, 21, 247-277. [CrossRef]

70. Thorndike, R.L. Who Belongs in the Family? Psychometrika 1953, 18, 267-276. [CrossRef]

71. McCormack, G.R.; Rock, M.; Toohey, A.M.; Hignell, D. Characteristics of urban parks associated with park use and physical activity: A review of qualitative research. Health Place 2010, 16, 712-726. [CrossRef] [PubMed]

72. Chen, S.; Sleipness, O.; Xu, U.; Park, K.; Christensen, K. A systematic review of alternative protocols for evaluating non-spatial dimensions of urban parks. Urban For. Urban Green. 2020, 53, 126718. [CrossRef]

73. Kaczynski, A.T.; Wilhelm Stanis, S.A.; Besenyi, G.M. Development and testing of a community stakeholder park audit tool. Am. J. Prev. Med. 2012, 42, 242-249. [CrossRef]

74. Bedimo-Rung, A.L.; Gustat, J.; Tompkins, B.J.; Rice, J.; Thomson, J. Development of a direct observation instrument to measure environmental characteristics of parks for physical activity. J. Phys. Act. Health 2006, 3, S176-S189. [CrossRef] [PubMed]

75. Saelens, B.E.; Frank, L.D.; Auffrey, C.; Whitaker, R.C.; Burdette, H.L.; Colabianchi, N. Measuring physical environments of parks and playgrounds: EAPRS instrument development and inter-rater reliability. J. Phys. Act. Health 2006, 3, S190-S207. [CrossRef] [PubMed] 
76. Chandrasiri, O.; Arifwidodo, S. Inequality in Active Public Park: A Case Study of Benjakitti Park in Bangkok, Thailand. Procedia Eng. 2017, 198, 193-199. [CrossRef]

77. Wissink, B.; Hazelzet, A. Bangkok living: Encountering others in a gated urban field. Cities 2016, 59, 164-172. [CrossRef]

78. Srichuae, S.; Nitivattananon, V.; Perera, R. Aging society in Bangkok and the factors affecting mobility of elderly in urban public spaces and transportation facilities. IATSS Res. 2016, 40, 26-34. [CrossRef] 